\title{
Can $x$ rays be accurately interpreted using a low cost telemedicine system?
}

\author{
Seamus O'Reilly, Ruth Spedding, Christine Dearden, Maria Loane
}

\begin{abstract}
Objective-To assess whether the quality of $x$ ray films transmitted via a low cost (low resolution) telemedicine link was satisfactory for clinical diagnosis.

Methods-A retrospective study of a set of consecutive accident and emergency (A\&E) radiographs. An A\&E registrar viewed these directly on a standard $x$ ray viewing box and via a telemedicine link. Results-There were 81 abnormalities out of $234 x$ ray films. Three abnormalities were missed both on the $\boldsymbol{x}$ ray viewing box and telemedicine link, one of which was significant. There were five additional abnormalities missed on the telemedicine link but detected on the $x$ ray viewing box, of which two were significant. One normal $x$ ray film was interpreted as abnormal on the telemedicine link. There were no false positives on direct viewing.

Conclusion-Transference of plain radiographs using a low cost/low resolution telemedicine link by A\&E doctors is adequate for clinical interpretation. (F Accid Emerg Med 1998;15:312-314)
\end{abstract}

Keywords: $x$ ray films; telemedicine

When a teleconsultation link was set up in 1994 between an accident and emergency (A\&E) department and a minor treatment centre, it was found that $22 \%$ of the teleconsultations involved the interpretation of plain $x$ ray films. ${ }^{1}$

Recent advances in digital imaging have provided high quality $x$ ray transmission and these high resolution systems are now accepted as the gold standard for teleradiology. ${ }^{2}$ At present the cost of these systems are prohibitive to smaller hospitals, minor treatment centres, and general practitioners. This prompted us to investigate the adequacy of a low cost telemedicine link for $x$ ray transmission.

\section{Eccident and}

Department, Royal

Victoria Hospital,

Belfast

C Dearden

Department of Telemedicine and Telecare, Queens University Belfast, Belfast City Hospital M Loane

Correspondence to: Dr O'Reilly, Specialist Registrar.

Accepted for publication 27 June 1998 A\&E department.

They were divided into two groups: in group A films were viewed first on the telemedicine link and subsequently on a $x$ ray viewing box and in group $B$ they were viewed first on the viewing box and then on the telemedicine link. All the $x$ ray films were subsequently seen by a consultant radiologist; the study was per- formed by two specialist registrars in $A \& E$ medicine.

One of the registrars was responsible for giving a brief clinical history, relevant clinical findings, and operation of the equipment. The other registrar was asked to interpret the films. The diagnoses were recorded on a proforma.

There was a time interval of seven days between viewing the same radiograph on the viewing box and via the telemedicine link. The radiographs were also presented in a different sequence over the two systems. This was to prevent recall of the previous interpretation.

The films were viewed on a standard $x$ ray viewing box (luminance 5500 lux), without a high intensity light source and in normal room lighting. A hand held modified domestic camcorder (Sharp VL $\mathrm{H} 400 \mathrm{H}$ ), incorporating $\times 8$ auto zoom lens was manually focused at the films on the viewing box. The camera was operated by the $A \& E$ registrar after a five minute training session.

The received analog signal was then converted to digital form by a Codec converter built into the videoconferencing unit VC 7000BT. This signal was transmitted over an integrated services digital network (ISDN) at $128 \mathrm{Kbits} / \mathrm{s}$, to an identical videoconferencing unit where it was reconverted to analog form. The image was then displayed on a 10" colour monitor with a resolution of 352 pixels $\times 288$ lines. The registrar interpreting the $x$ ray images directed the use of the zoom feature on the camera. This magnified specific areas on the original image, allowing small portions of the radiograph to fill the entire screen.

One of the problems using the hand held camera was picture shake causing blurring of the image on the screen. This was largely resolved using the still frame and strobe lighting facility of the camera. The tripod was not used because we found this prevented easy and rapid movement of the camera to focus on different areas of the $x$ ray.

The registrar who viewed the $x$ ray films was not told of the radiologist's report until the study was completed. At the end of the study both registrars reviewed all the $x$ ray films for any significant abnormalities not documented on the official report. These significant abnormalities were independently confirmed by two consultants (one in $\mathrm{A} \& \mathrm{E}$ medicine and the other in radiology).

\section{Results}

There were a total of 210 patients in the study who generated $234 x$ ray films: the first 105 patients (group A) produced 118 and the other 105 (group B) produced 116 films. 
The figures contained five significantly abnormal films that were not initially recorded on the official $x$ ray report (four in group $A$ and one in group B).

Group A was transmitted first by video link. The A\&E registrar detected $34 / 42$ (81\%) of the abnormal films in this group compared with $39 / 42(93 \%)$ subsequently on direct vision. There were no false positives in group A. Prevalence of abnormal radiographs in group A was $36 \%$.

Table 1 shows the sensitivity (that is, the proportion of true positives identified), specificity (that is, the proportion of true negatives correctly identified), positive predictive value

Table 1 Sensitivity, specificity, positive predictive value, and negative predictive values of the two groups

\begin{tabular}{lllll}
\hline & Sensitivity (\%) & Specificity (\%) & $\begin{array}{l}\text { Positive } \\
\text { predictive } \\
\text { value (\%) }\end{array}$ & $\begin{array}{l}\text { Negative } \\
\text { predictive } \\
\text { value (\%) }\end{array}$ \\
\hline Group A & & & & \\
$\quad$ Viewing box & 93 & 100 & 100 & 96 \\
$\quad$ Telemedicine link & 81 & 100 & 100 & 91 \\
Group B & 100 & 100 & 100 & 100 \\
$\quad$ Viewing box & 90 & 99 & 97 & 95 \\
Telemedicine link & 90 & &
\end{tabular}

Table 2 Abnormalities in each group

\begin{tabular}{|c|c|c|c|}
\hline \multicolumn{2}{|l|}{ Group $A$} & \multicolumn{2}{|l|}{ Group B } \\
\hline Non-trauma & & Non-trauma & \\
\hline Chest & & Chest & \\
\hline Apical calcification & 1 & Apical tuberculosis & 1 \\
\hline Left ventricular failure & 4 & Pleural effusion (small) & 1 \\
\hline Plate atelectasis & 1 & Cardiomegaly & 1 \\
\hline Pleural effusion & 1 & & \\
\hline Lesion right lung field & 1 & & \\
\hline Abdomen & & Abdomen & \\
\hline Massive right kidney & 1 & Opacity renal tract & 2 \\
\hline Gall stones & 2 & Gall stones & 1 \\
\hline Foreign body GI tract & 1 & & \\
\hline Opacity LUQ & 1 & & \\
\hline Dilated loop colon ? pancreatitis & 1 & & \\
\hline Knee & & Knee & \\
\hline Effusion & 1 & Effusion & 1 \\
\hline Calcification MCL & 1 & Calcification MCL & 1 \\
\hline Osteoarthritis & & Osteoarthritis & \\
\hline Toe & 1 & Calcification supraspinatus tendon & 1 \\
\hline Lumbar spine & 1 & Shoulder & 1 \\
\hline Cervical spine & 1 & A-C joint & 1 \\
\hline Hip & 1 & Cuboid & 1 \\
\hline & & MTP joint & 1 \\
\hline & & Index finger & 1 \\
\hline & & Lumbar spine & 1 \\
\hline & & Miscellaneous & \\
\hline & & Sudeck's atrophy foot & 1 \\
\hline Trauma & & Trauma & \\
\hline Shoulder & & Shoulder & \\
\hline \# Greater tuberosity (undisplaced) & 2 & \# Distal humerus (undisplaced) & 1 \\
\hline \# Humerus & 1 & \# Clavicle & 2 \\
\hline \# Scapula & 1 & & \\
\hline \# Mid-clavicle (undisplaced) & 1 & & \\
\hline Wrist elbow and hand & & Wrist elbow and hand & \\
\hline \# Distal radius/ulna (undisplaced) & 3 & Colles' \# wrist & 2 \\
\hline Flake \# distal humerus & 1 & Greenstick \# radius & 1 \\
\hline Greenstick \# radius & 1 & \# 5th metacarpal (base) & 1 \\
\hline Avulsion \# triquetrum & 1 & Old \# 5th metacarpal & 2 \\
\hline \# Phalanx (undisplaced) & 2 & \# Proximal phalanx fingers & 3 \\
\hline \# Mid-radius/ulna & 1 & \# Base distal phalanx finger & 3 \\
\hline Volar plate \# & $i$ & \# Radial head (undisplaced) & 2 \\
\hline Ulnar collateral ligament injury & 1 & Knee & \\
\hline \# Radial head (undisplaced) & 1 & Effusion & 1 \\
\hline Chest & & Foot & 0 \\
\hline \# 8th and 9th ribs & 1 & \# Toe phalanx & 2 \\
\hline Ankle & & Avulsion \# base 5th metatarsal & 1 \\
\hline \# Lateral malleolus & 3 & Spine & \\
\hline Miscellaneous & & Wedge \# T5 & 1 \\
\hline \# Transverse process $\mathrm{L4}$ & 1 & Wedge \# L3 & 1 \\
\hline Total No & 42 & Total No & 39 \\
\hline
\end{tabular}

$\mathrm{A}-\mathrm{C}=$ acromio-clavicular; $\#=$ fracture; $\mathrm{GI}=$ gastrointestinal; $\mathrm{LUQ}=$ left upper quadrant; $\mathrm{MCL}=$ medial collateral ligament; $M T P=$ metotarsophalangeal. (that is, the proportion of patients with an abnormality present correctly diagnosed), and the negative predictive value (that is, the proportion of patients with no abnormality present correctly diagnosed) for group A.

The five abnormalities missed solely by the video link were: fractures of the left eighth and ninth ribs (on the one $x$ ray), a chip off the triquetrum, a volar plate fracture of a finger, a new fracture at the site of an old fracture at the lateral malleolus, and a grossly enlarged right kidney. The last two were also not noted on the official $x$ ray report.

There were three abnormal radiographs missed by both direct vision and using the video link: a fracture at the base of the third metatarsal, an undisplaced fracture of the lateral humeral condyle, and a fracture of the wing of the scapula (on an anteroposterior shoulder film). The last two were not recorded on the official $x$ ray report.

Group B was initially viewed using a standard $x$ ray viewing box. The A\&E registrar detected 39/39 (100\%) of the abnormal films in this group on direct viewing compared with $35 / 39(90 \%)$ subsequently over the video link. There was one false positive on viewing of group B over the video link: an avulsion of the base of the fifth metatarsal. The prevalence of abnormal films in group B was 34\%. Table 1 shows the sensitivity, specificity, positive predictive value, and negative predictive value for group B.

The four abnormalities missed using the video link were: an undisplaced fracture of distal radius, a fracture of the base of the fifth metacarpal with an old boxer's fracture, an undisplaced fracture through the base of the fifth metatarsal, and an opacity of the left renal tract. Table 2 shows the abnormalities present in each group.

The $\mathrm{K}$ statistic gives the level of agreement between the two methods used to view the films in groups A and B combined compared with the gold standard (that is, the radiologist's $x$ ray report). A value of $>0.81$ signifies a very good agreement between the groups. The $\kappa$ value for the video link is 0.87 and that for the viewing box 0.98 .

\section{Discussion}

The ability to transfer and interpret radiological images from a distant site, for example a minor injury unit run by nurse practitioners, has undergone remarkable advances in recent years. Relative success has been reported in applying relatively low resolution teleradiology systems to remote interpretation of nuclear radiology. ${ }^{3}$ Previous studies have questioned the use of these low resolution systems in the interpretation of plain $x$ ray films. ${ }^{45}$ The recently published standard of the American College of Radiology for teleradiology specifies $2000 \times 2000$ pixel resolution for definitive interpretation. $^{2}$ Unlike film digitisers, the system we used involved image transmission by pointing a video camera at the plain $x$ ray film mounted on a viewing box.

We found that the system could be practically used in normal room lighting conditions 
without much loss in definition of the image. This contrasts with previous studies which have used quiet dark reporting room conditions. ${ }^{5}$ The number of significant "misses" was low when $x$ rays were viewed in conjunction with a good clinical history. Appropriate treatment and follow up was given in all cases save one.

The improvised camcorder proved easy to operate. The sender could act upon all instructions given by the $\mathrm{A} \& \mathrm{E}$ specialist.

There were 13 films that would have been difficult to see without the strobe lighting and still frame facility on the camcorder. Soft tissue swelling seen on the viewing box could not be visualised easily over the video link. Joint effusions however were well seen.

It took, on average, three times longer to interpret $x$ ray films on the video link compared with direct viewing. Because of the interactive nature of the telemedicine system the length of a typical consultation varied considerably even for similar films shown. This depended largely on the nature of the complaint and physical signs elicited. This is similar to that found in a previous study. ${ }^{6}$ Chest radiographs proved to be particularly time consuming.

A\&E specialists place a greater reliance on an adequate and accurate clinical history in order to interpret $x$ ray images correctly. ${ }^{7}$ In a busy $A \& E$ department which is the receiving centre for these images there are implications for middle grade/senior A\&E medical staff. It has been discovered that when a telemedicine link was used to provide support for a nurse run minor injuries unit seeing 6729 patients per year, that it was used approximately only once a week. This was thought to be due both to increased staff confidence resulting from the presence of the link and a learning/feedback effect. ${ }^{1}$

We used randomised sampling that did not include some important subtle findings such as apical pneumothoraces, spinal fractures, skull fractures, and facial injuries. ${ }^{8-10}$ We do not suggest that the video link replaces a definitive $x$ ray report but rather is used as part of the teleconsultation process and when all the information is presented it is used to implement a safe and effective treatment plan.
Installation of ISDN2 lines cost approximately $£ 550$ (December 1996). This includes both the connection charge $(£ 199)$ and the yearly rental cost $(£ 352)$. Call charges are twice the price of a normal telephone call. The videoconferencing units used retailed at $£ 6000$ per unit. The video camera cost was approximately $£ 750$. Thus the total installation cost for the system used in the study is $£ 12950$. This compares to the cost of a high resolution digital network costing approximately $£ 40000$.

Further studies are required to look at larger numbers of $x$ ray films comparing different systems and different grades of medical specialists. This is part of a larger study planned for the future.

In conclusion we realise the limits of the system, but when used as part of an overall teleconsultation process we feel it is of value to the A\&E specialist and patient alike.

The authors thank Dr Liz Dowey, consultant in accident and emergency medicine, Belfast City Hospital; Dr John Lawson, consultant radiologist, Belfast City Hospital; and Professor Richard Wooton, Department of Telemedicine and Telecare, Queens University Belfast.

1 Darkins A, Dearden CH, Rocke LG, et al. An evaluation of telemedical support for a minor treatment centre. Journal of Telemedicine and Telecare 1996:2:93-9.

2 American College of Radiology. ACR standard for teleradiology. Reston, VA: ACR, 1994

3 Arnstein NB, Chen DCP, Siegal ME. Interpretation of bone scans using a video display: a necessary step toward a filmless nuclear medicine department. Clin Nucl Med 1990;15:418-23.

4 Scott WW, Rosenbaum JE, Ackerman SJ, et al. Subtle orthopedic fractures: teleradiology workstation versus film interpretion. Radiology 1993;187:811-15.

5 Scott WW Jr, Bluemke DA, Mysko WK, et al. Interpretation of emergency department radiographs by radiologists and emergency medicine physicians: teleradiology workstation versus radiograph readings. Radiology 1995;195:223-9.

6 De Corato DR, Kagetsu NJ, Ablow RC. Off-hours interpretation of radiologic images of patients admitted to the emergency department; efficacy of teleradiology. AJR 1995;165:1293-6.

7 Berbaum KS, Franken EA Jr, El-Khoury GY. Impact of clinical history on radiographic detection of fractures: a comparison of radiologists and orthopedists. AJR 1989; 153:1221-4

8 Yoshino MT, Carmody R, Fajardo LL, et al. Diagnostic performance of teleradiology in cervical spine fracture detection. Invest Radiol 1992;27:55-9.

9 Elam EA, Rehm K, Hillman BJ, et al. Efficacy of digital radiology for the detection of pneumothorax: comparison with conventional radiography. AJR 1992;158:509-14.

10 Murphey MD, Bramble JM, Cook LT, et al. Nondisplaced fractures: spatial resolution requirements for detection with digital skeletal imaging. Radiology 1990;174:865-70. 